Check for updates

Cite this: Mater. Adv., 2022, 3, 1263

Received 21st October 2021. Accepted 3rd December 2021

DOI: 10.1039/d1ma00976a

rsc.li/materials-advances

\title{
Mixed-dimensional organic-inorganic metal halide perovskite (OIMHP) based gas sensors with superior stability for $\mathrm{NO}_{2}$ detection $\dagger$
}

\author{
The Duong, (ID $\ddagger^{*^{a}}$ Alishba T. John, (D) $\ddagger^{\mathrm{b}}$ Hongjun Chen, ${ }^{\star c}$ Huyen Pham, ${ }^{d}$ \\ Krishnan Murugappan, (D) ${ }^{\mathrm{b}}$ Thanh Tran-Phu, ${ }^{\text {be }}$ Antonio Tricoli (D) ${ }^{\text {be }}$ and \\ Kylie Catchpole ${ }^{a}$
}

\begin{abstract}
Organic-inorganic metal halide perovskite (OIMHP) materials have been intensively investigated for optoelectronic applications, especially in solar cells. Here, we investigate OIMHP materials for gas sensor application to detect $\mathrm{NO}_{2}$ gas, a harmful gas for humans and the environment. As a control, although the three-dimensional (3D) OIMHP $\mathrm{NO}_{2}$ gas sensors exhibit good performance toward $\mathrm{NO}_{2}$ gas when operating at room temperature, ambient stability remains the bottleneck for practical application. Using dimensional engineering of the OIMHP materials, not only the ambient stability but also the performance of the perovskite sensors has been greatly improved. The mixed-dimensional 2D/3D OIMHP gas sensors show an excellent sensitivity of $6.3 \pm 0.83$ times per ppm $\mathrm{NO}_{2}$, good selectivity toward $\mathrm{NO}_{2}$ gas, and quick response and recovery times of $5.7 \mathrm{~s}$ and $12.7 \mathrm{~s}$, respectively. More importantly, the sensor performance can be stable under ambient conditions for almost two months, much longer than the control 3D-only device (13 days). The work paves the way for the development of perovskite based $\mathrm{NO}_{2}$ gas sensors with superior stability and excellent performance at room temperature.
\end{abstract}

\section{Introduction}

Nitrogen dioxide $\left(\mathrm{NO}_{2}\right)$ gas is deadly to humans as the gas can cause serious health issues even in extremely low concentrations $\left(<10\right.$ parts per million (ppm)). ${ }^{1,2}$ In addition, the gas is also harmful to the environment since it can react with other pollutants or water in the environment to generate ozone and acid rain. ${ }^{3,4}$ Therefore, it is critical to reliably detect trace amounts of $\mathrm{NO}_{2}$ gas. Over the past few decades, extensive research work on $\mathrm{NO}_{2}$ gas sensors has been carried out. Various materials have been used to fabricate $\mathrm{NO}_{2}$ gas sensors, each with distinctive performance and stability depending on the material properties, deposition techniques and sensor designs.

\footnotetext{
${ }^{a}$ School of Engineering, The Australian National University, Canberra 2601, Australia.E-mail: the.duong@anu.edu.au, hongjun.chen@sydney.edu.au

${ }^{b}$ Nanotechnology Research Laboratory, Research School of Chemistry, College of Science, The Australian National University, Canberra 2601, Australia

${ }^{c}$ The University of Sydney Nano Institute (Sydney Nano) and School of Physics, University of Sydney, Sydney 2006, Australia

${ }^{d}$ Department of Electronic Materials Engineering, Research School of Physics, The Australian National University, Canberra 2601, Australia

${ }^{e}$ Nanotechnology Research Laboratory, School of Biomedical Engineering,

Faculty of Engineering, the University of Sydney, Sydney 2006, Australia

$\dagger$ Electronic supplementary information (ESI) available. See DOI: 10.1039/ d1ma00976a

\$ These authors contributed equally.
}

These include polymers, ${ }^{5-8}$ carbon-based nanomaterials (i.e. carbon black ${ }^{9}$ carbon nanotubes, ${ }^{10,11}$ and graphene ${ }^{12,13}$ ), metal oxides, ${ }^{14-18}$ and $2 \mathrm{D}$ transition metal di-chalcogenides. ${ }^{19}$ Despite considerable progress, it is still required to find a new material to develop $\mathrm{NO}_{2}$ gas sensors which can operate at room temperature with excellent performance/stability and at the same time is easy to miniaturize for on-chip integration.

Organic-inorganic metal halide perovskite (OIMHP) materials have recently attracted tremendous interest for various optoelectronic applications especially in solar cells and lightemitting diodes (LEDs). This is due to the simple deposition process and excellent optoelectronic properties including the sharp optical absorption edge and low non-radiative recombination loss leading to remarkable photoluminescence quantum efficiency of the OIMHP materials. ${ }^{20-22}$ Although the sensitive nature of OIMHP materials creates challenges for the fabrication of stable solar cells and LEDs, ${ }^{23,24}$ this property makes OIMHP materials good candidates for chemical sensing applications. ${ }^{25}$ As a result, OIMHP materials have recently been investigated for the detection of oxygen,${ }^{26}$ ozone, ${ }^{27}$ multiple volatile organic compounds (VOCs) i.e. acetone, ethanol, and ammonia, ${ }^{26,28}$ and $\mathrm{NO}_{2}$ gas. ${ }^{29-31}$ In the chemical sensing applications, the stability of the sensor devices in an ambient environment with the presence of moisture is the main challenge for their practical implementation given that the sensors 
cannot be encapsulated. Therefore, it is essential to develop OIMHP based gas sensors with superior ambient stability.

In this work, we employed a dimensional engineering strategy to tackle the ambient stability of OIMHP based gas sensors for the detection of $\mathrm{NO}_{2}$. A large organic cation n-octylammonium bromide was applied to passivate the three-dimensional (3D) perovskite, ${ }^{32,33}$ resulting in a mixed-dimensional $2 \mathrm{D} / 3 \mathrm{D}$ perovskites with greatly improved resistance to moisture degradation. By virtue of the heterojunction structure, this $2 \mathrm{D} / 3 \mathrm{D}$ perovskite based gas sensor also shows much enhanced sensor response toward $\mathrm{NO}_{2}$ gas compared to its 3D counterpart. As a result, the mixed-dimensional OIMHP based gas sensors not only show excellent performance for $\mathrm{NO}_{2}$ detection but also demonstrate very good ambient stability, paving a way for practical applications.

\section{Materials and methods}

\section{Materials}

Formamidinium iodide (FAI), formamidinium bromide (FABr), methylammonium iodide (MAI), methylammonium bromide (MABr), and $n$-octylammonium bromide ( $n$-OABr) were ordered from GreatCell Solar Materials. Other materials were ordered from Sigma Aldrich.

\section{Methods}

Fabrication of perovskite sensors. Indium-doped tin oxide (ITO) glass substrates were cut into $10 \mathrm{~mm} \times 10 \mathrm{~mm}$ pieces. Isolation lines were created using a laser to separate two electrodes on a single substrate. The substrates were cleaned with detergent for 90 minutes and for 15 minutes in acetone, 2-propanol, and ethanol sequentially. The substrates were further cleaned using UV ozone for 30 minutes before being immediately transferred to a $\mathrm{N}_{2}$ purging glove box. $1 \mathrm{ml}$ of $3 \mathrm{D}$ perovskite precursor was prepared by mixing $0.75 \mathrm{ml}$ of FAPbI $_{2} \mathrm{Br}$ (1.3 M in DMF/DMSO $4: 1$ volume ratio), $0.15 \mathrm{ml}$ $\mathrm{MAPbI}_{2} \mathrm{Br}$ (1.3 $\mathrm{M}$ in DMF/DMSO $4: 1$ volume ratio), $0.1 \mathrm{ml}$ $\mathrm{CsPbI}_{2} \mathrm{Br}$ (1.3 $\mathrm{M}$ in DMSO) and $0.05 \mathrm{ml} \mathrm{RbI}$ (1.3 $\mathrm{M}$ in DMSO). The $3 \mathrm{D}$ perovskite was deposited on the substrates by spinning $40 \mu \mathrm{L}$ of the solution at $1000 \mathrm{rpm}$ for $10 \mathrm{~s}$ (acceleration rate $100 \mathrm{rpm} \mathrm{s}^{-1}$ ) and $4000 \mathrm{rpm}$ (acceleration rate $1000 \mathrm{rpm} \mathrm{s}^{-1}$ ) for $20 \mathrm{~s} .5 \mathrm{~s}$ before the program ends, $150 \mu \mathrm{L}$ of chlorobenzene was quickly dropped in the middle of the substrates. This was then followed by annealing at $100{ }^{\circ} \mathrm{C}$ on a hotplate for 30 minutes. $90 \mu \mathrm{L}$ of $n$-octylammonium bromide diluted in 2-propanol with different concentrations $\left(2.5 \mathrm{mg} \mathrm{ml} \mathrm{ml}^{-1}, 5.0 \mathrm{mg} \mathrm{ml} \mathrm{m}^{-1}\right.$, and $10.0 \mathrm{mg} \mathrm{ml}^{-1}$ ) was dynamically spun on top of the 3D perovskite substrates at $5000 \mathrm{rpm}$ for $30 \mathrm{~s}$. The substrates were further annealed at $100{ }^{\circ} \mathrm{C}$ for 5 minutes. Au metal contact was deposited on the substrates by thermal evaporation through a shadow mask.

\section{Characterization}

Material characterization. Scanning electron microscopy (SEM) imaging was performed on an FEI Verios system. Grazing incidence X-ray diffraction (GIXRD) was measured with a highresolution PANalytical X'Pert PRO MRD system with a step size of $0.005^{\circ}$ and an integration time of $1 \mathrm{~s}$ per step. The absorbance was measured with a Lambda 1050 spectrophotometer (PerkinElmer) in an integrating sphere mode. Transmission electron microscopy (TEM) analyses were performed using a JEOL $2100 \mathrm{~F}$ instrument. Steady state photoluminescence measurements and time-resolved photoluminescence measurements were performed using a LabRAM HR Evolution system with a time-correlated single photon counting (TCSPC) system (DeltaPro-DD, Horiba). A $508 \mathrm{~nm}$ diode laser (DD-510L, Horiba) with a pulse duration of $110 \mathrm{ps}$ and a fluence of $\sim 10 \mu \mathrm{J} \mathrm{cm} \mathrm{cm}^{2}$ per pulse, and a repetition rate of $312.5 \mathrm{kHz}$ was used for excitation. Photoluminescence images of perovskite films were taken following the procedure reported in our previous work. ${ }^{34,35}$

Chemiresistive gas sensing characterization. $\mathrm{NO}_{2}(10 \mathrm{ppm}$ in $\mathrm{N}_{2}$ (Coregas)), ethanol (10 ppm in $\mathrm{N}_{2}$ (Coregas)), acetone (10 ppm in $\mathrm{N}_{2}$ (Coregas)), propane (10 ppm in $\mathrm{N}_{2}$ (Coregas)), ethyl benzene (10 ppm in $\mathrm{N}_{2}$ (Coregas)), and carbon dioxide (10 ppm in $\mathrm{N}_{2}$ (Coregas)) diluted in simulated air $\left(2 \mathrm{~L} \mathrm{~min}{ }^{-1}\right.$ $\mathrm{O}_{2}+0.8 \mathrm{~L} \mathrm{~min}^{-1} \mathrm{~N}_{2}$ (BOC Ltd)) were controlled using a mass flow controller (Bronkhorst) to obtain the desired concentration range $(2-8 \mathrm{ppm})$ while the total flow rate of the gas was kept constant at $1 \mathrm{~L} \mathrm{~min}^{-1}$. The temperature of the hotplate in the gas sensing chamber (Linkam) was kept constant at $25{ }^{\circ} \mathrm{C}$ using a temperature controller. The dynamic responses were recorded using an electrochemical workstation (CHI 660E, USA) at a constant applied voltage of $1 \mathrm{~V}$. The sensor response is calculated based on the following formula:

$$
S=\left[\frac{I_{\text {analyte }}}{I_{\text {air }}}\right]-1
$$

where $I_{\text {analyte }}$ and $I_{\text {air }}$ are the current of the sensor under target gas and simulated air conditions respectively. The sensor sensitivity is defined as the slope of the graph representing the change of the sensed current $v s$. the gas concentration. The response time and recovery time are the time required for the sensed current to change to $90 \%$ of its saturated value since the time the gas is on and off, respectively. Humidity tests were performed by supplying water vapour into the system via an air flow through a bubbler.

\section{Results and discussion}

Fig. 1a illustrates the steps to fabricate mixed-dimensional perovskite films. First, the $3 \mathrm{D}$ perovskite is deposited on the substrates by spin coating and the black $3 \mathrm{D}$ perovskite phase is formed after annealing at $100{ }^{\circ} \mathrm{C}$ for 30 minutes. Second, a passivation solution containing the long alkylammonium chain organic cation $n$-octylammonium bromide ( $n$-OABr) $\mathrm{C}_{8} \mathrm{H}_{20} \mathrm{NBr}$ layer is deposited on top of the $3 \mathrm{D}$ perovskite film to form a mixed 2D/3D perovskite film after short annealing at $100{ }^{\circ} \mathrm{C}$ for 5 minutes. Fig. 1b shows a simple top-bottom electrode configuration of a perovskite sensor device. Given that all the layers can be deposited at temperature lower than $150{ }^{\circ} \mathrm{C}$, this 


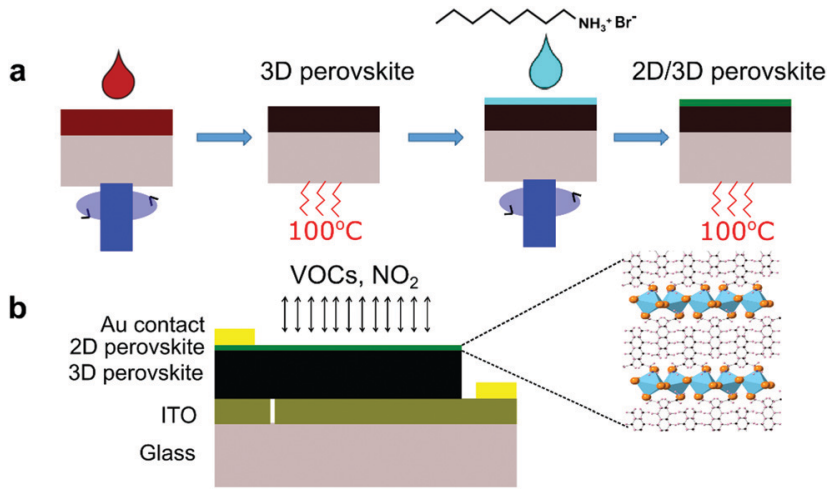

Fig. 1 (a) Scheme showing the fabrication steps for the mixeddimensional perovskite films on ITO glass substrates. (b) Top-bottom electrode configuration of perovskite sensor devices for $\mathrm{NO}_{2}$ detection.

structure can be potentially implemented on flexible substrates as wearable sensors.

\section{Improvement in the performance of mixed-dimensional perovskite-based gas sensors}

The gas sensing performance of the $3 \mathrm{D}$ and $2 \mathrm{D} / 3 \mathrm{D}$ perovskite sensors was tested toward various analyte gases namely $\mathrm{NO}_{2}$, ethanol, acetone, propane, and ethyl benzene. As shown in Fig. 2a, the 3D perovskite sensor device exhibits a good sensor response to $\mathrm{NO}_{2}$ accompanied by the increase in the current during the injection of 2-8 ppm of $\mathrm{NO}_{2}$ gas at room temperature. The corresponding response and recovery times were measured to be $11.9 \mathrm{~s}$ and $12.9 \mathrm{~s}$, respectively (Fig S1a, ESI $\dagger$ ). In the 3D perovskite composition, the primary and secondary amines are present in the formamidinium cation $\left(\mathrm{CH}\left(\mathrm{NH}_{2}\right)_{2}\right)$ and primary amine in the methylammonium cation $\left(\mathrm{CH}_{3} \mathrm{NH}_{3}\right)$. Therefore, it is expected that the electron donor interaction among $\mathrm{NO}_{2}$ gas with the amine groups in the $3 \mathrm{D}$ perovskite is responsible for the working mechanism as reported previously. ${ }^{36}$ In comparison, the 2D/3D perovskite sensor device shows greatly enhanced sensor response and the current increases by up to 50 times while being exposed to $8 \mathrm{ppm}$ of $\mathrm{NO}_{2}$ (Fig. 2b). Based on the sensor response curves shown in Fig. $2 \mathrm{c}$ and $\mathrm{d}$, the sensitivity of the $2 \mathrm{D} / 3 \mathrm{D}$ perovskite sensor was calculated to be $6.3 \pm 0.83$ times per ppm as compared to the sensitivity of $1.25 \pm 0.16$ times per ppm in the control 3D-only device. The response time and recovery time in the $2 \mathrm{D} / 3 \mathrm{D}$ perovskite sensor device are reduced to $5.7 \mathrm{~s}$ and $12.7 \mathrm{~s}$, respectively (Fig. S1b, ESI $\dagger$ ). The $2 \mathrm{D} / 3 \mathrm{D}$ perovskite device was tested toward sub-ppm $\mathrm{NO}_{2}$ concentrations. The device shows the response of 0.04 and 0.19 toward $0.2 \mathrm{ppm}$ and $0.4 \mathrm{ppm} \mathrm{NO}_{2}$, respectively (Fig. S2, ESI $\dagger$ ). As summarized in Table S1 (ESI $\dagger$ ), the 2D/3D perovskite sensor in this work has comparable responsivity and slightly faster response/recovery time compared to room temperature operation metal oxide-based $\mathrm{NO}_{2}$ gas sensors. Although metal oxide based $\mathrm{NO}_{2}$ sensors generally show a very low detection limit, we note that many of them require light activation. We tested the 2D/3D perovskite devices toward $8 \mathrm{ppm} \mathrm{NO}_{2}$ in the presence of light and directly compared that with the sensor response in the dark. The device was illuminated through a quartz window using a solar simulator (NewSpec, LCS-100) with an intensity of $100 \mathrm{~mW} \mathrm{~cm}{ }^{-2}$. We found that the responsivity of the device was significantly reduced in the presence of light (Fig. S3, ESI $\dagger$ ). Previous reports have demonstrated that when chemiresistive sensors with light sensitive active layers operate under light, the light-activated adsorption processes compete with a light-activated desorption around the oxygen adsorbates. ${ }^{37,38}$ This resulted in complex changes in the response of the sensors depending on many factors such as the properties of the active layer, adsorption and photodesorption rates, etc. In this case, the presence of light significantly reduces the responsivity of the perovskite-based $\mathrm{NO}_{2}$ sensor. The exact mechanism underlying this phenomenon requires further investigation beyond the scope of this work. It is worth noting that the response in the 2D/3D sample gradually reduces after reaching saturation, when the gas is on, which would require further investigation. Nevertheless, 2D/3D perovskite sensors demonstrate much better sensor response than the 3D perovskite sensor device. In addition, both $3 \mathrm{D}$ and $2 \mathrm{D} / 3 \mathrm{D}$ perovskite sensors show very good selectivity toward $\mathrm{NO}_{2}$ gas after being tested with other analyte gases such as ethanol, acetone, propane, ethyl benzene, and carbon dioxide (Fig. 2e and f).

\section{Investigation on the surface morphology, phase formation and electronic properties}

To investigate the enhanced sensor performance, the morphology changes of the 3D perovskite layer upon passivation with the long alkyl chain organic cation $n$-OABr to form $2 \mathrm{D} / 3 \mathrm{D}$ perovskites was characterized using scanning electron microscopy (SEM). Fig. 3a presents the surface morphology of the 3D perovskite showing a compact layer with the grain size ranging from $100 \mathrm{~nm}$ to $500 \mathrm{~nm}$. It is worth noticing that the bright features on the surface of the films are related to a Rb-rich phase as in previous reports. ${ }^{39,40}$ With a low concentration of $2.5 \mathrm{mg} \mathrm{ml}^{-1}$ for the passivation precursor, the morphology of the perovskite film remains unchanged except that a very thin layer of new substance at the top of the film is evidenced by the changes in the SEM image contrast (Fig. 3b). As the concentration of the passivation increases to $5.0 \mathrm{mg} \mathrm{ml}^{-1}$ and $10.0 \mathrm{mg} \mathrm{ml}^{-1}$, the top layer becomes more obvious, indicating the formation of a new layer on the surface of the 3D perovskite (Fig. 3c and d). Energy dispersive X-ray spectroscopy (EDS) measurements were performed on the $3 \mathrm{D}$ and $2 \mathrm{D} / 3 \mathrm{D}$ (with $5.0 \mathrm{mg} \mathrm{m}^{-1}$ ) perovskite films. As shown in Note $\mathrm{S} 1$ (ESI $\dagger$ ), the 2D/3D perovskite film surface shows a higher atomic ratio of $\mathrm{C}$ and $\mathrm{N}$ compared to the $3 \mathrm{D}$ perovskite film surface. In addition, the atomic ratio of $\mathrm{Pb}$ in the $2 \mathrm{D} / 3 \mathrm{D}$ perovskite film surface is significantly lower than in the 3D perovskite film surface. Grazing incidence X-ray diffraction (GIXRD) in Fig. 3e shows the formation of a $2 \mathrm{D}$ phase at $2 \theta=3.55^{\circ}, 7.1^{\circ}, 10.65^{\circ}$ and $12.6^{\circ}$. These phases are related to the Ruddlesden-Popper $2 \mathrm{D}$ perovskite $n-\mathrm{OA}_{2} \mathrm{~Pb}\left(I_{x} \mathrm{Br}_{1-x}\right)_{4}$, which forms due to the reaction between the $n$-OA cation and the under-coordinated $\mathrm{Pb}$ on the $3 \mathrm{D}$ perovskite surface. ${ }^{41}$ When the concentration increases, the 2D perovskite peaks become more prominent indicating that a thicker $2 \mathrm{D}$ layer is formed. To determine the thickness of the 2D layer when the concentration of the 
3D

a

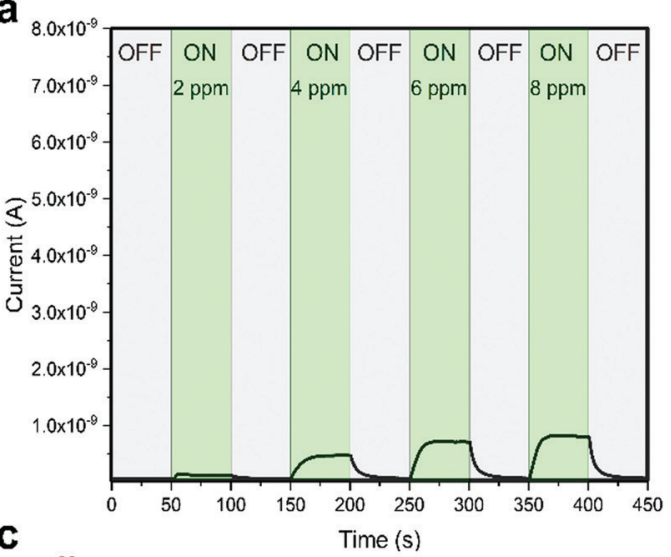

C

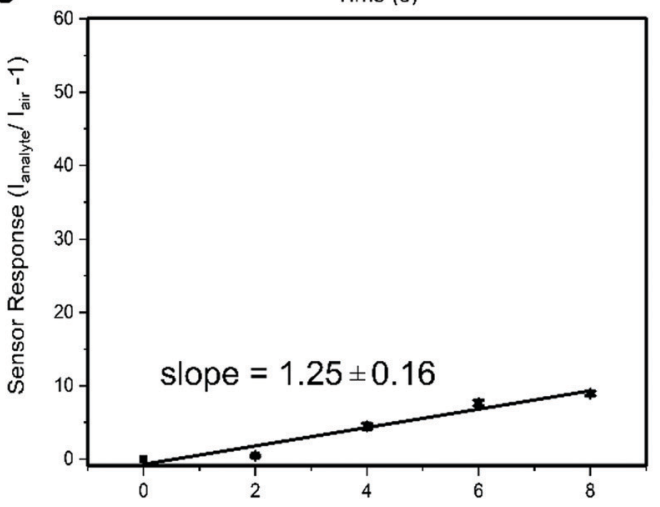

e

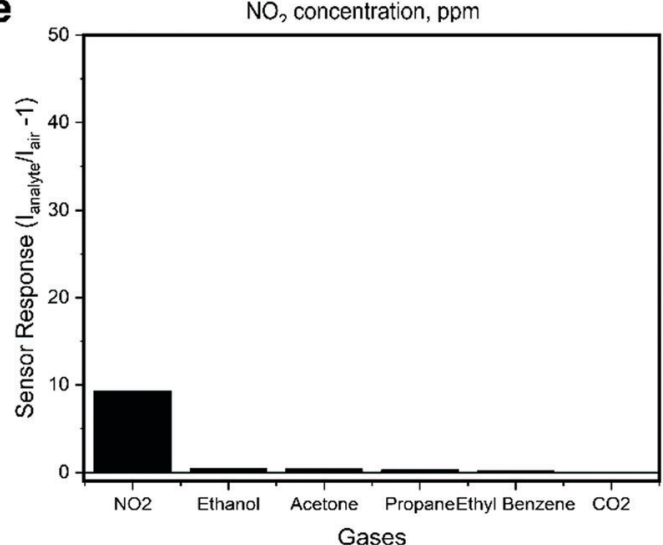

2D/3D
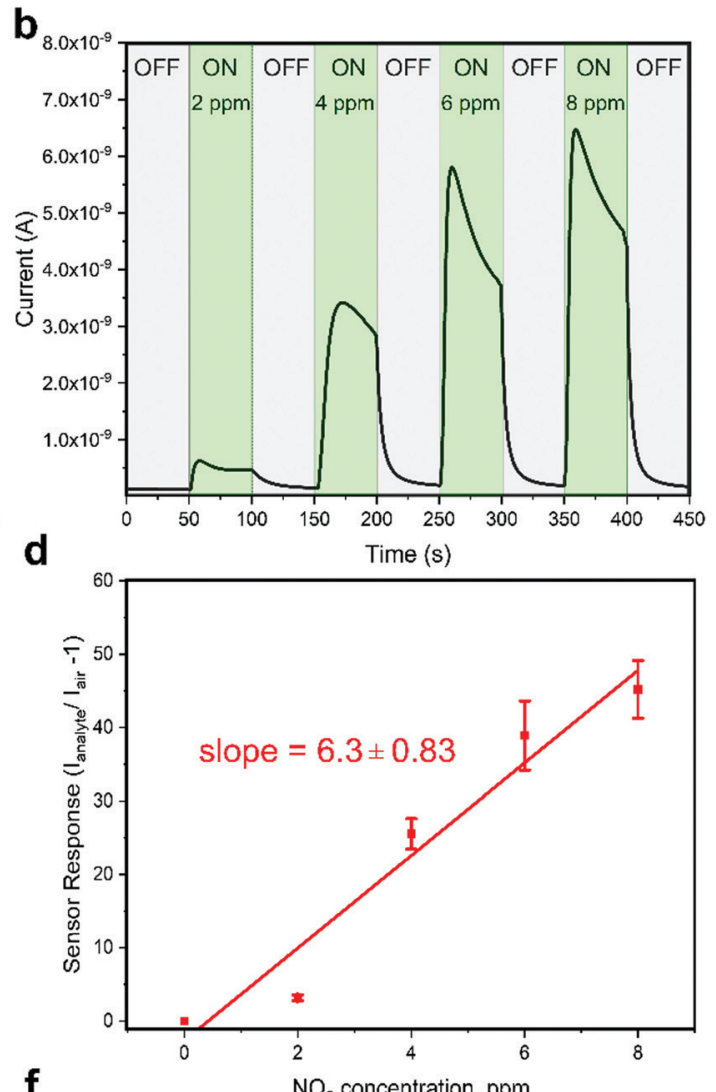

f

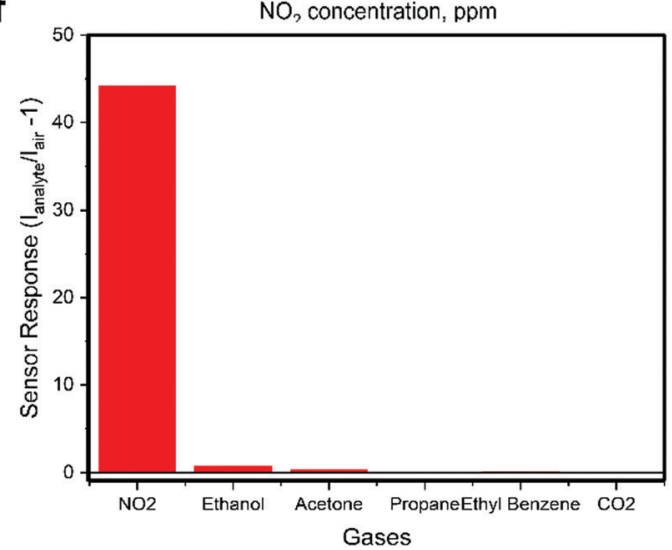

Fig. 2 Current responses of sensor devices with (a) 3D perovskite and (b) 2D/3D perovskite gas sensors under consecutive injections of $\mathrm{NO}_{2}$ gas with concentrations ranging from 2 to $8 \mathrm{ppm}$. Sensor responses of (c) 3D perovskite and (d) 2D/3D perovskite sensors as a function of the $\mathrm{NO}_{2}$ concentration. Selectivity testing of (e) 3D perovskite and (f) 2D/3D perovskite-based sensors under a group of gases including $\mathrm{NO}_{2}$, ethanol, acetone, propane, ethyl benzene, and carbon dioxide (with a concentration of 8 ppm).

passivation solution is $2.5 \mathrm{mg} \mathrm{ml} \mathrm{ml}^{-1}$, we used transmission electron microscopy (TEM) to examine the cross-section of the $2 \mathrm{D} / 3 \mathrm{D}$ sensor device. Although the $2 \mathrm{D}$ layer is ultrathin and it cannot be noticed in the low-magnification bright-field TEM (BF-TEM) image in Fig. 3f, it is evident that multiple phases with different interplanar spacings are present in the high-resolution TEM (HR-TEM) image in Fig. 3g. One phase with an interplanar spacing of $6.834 \AA$ is at the top surface layer. This phase is related to the new $2 \mathrm{D}$ peak at $2 \theta=12.6^{\circ}$. The location and size of this phase indicate that the thickness of the $2 \mathrm{D}$ layer is around
$20 \mathrm{~nm}$. With such a thin layer, we have shown that the $2 \mathrm{D}$ perovskite does not completely cover the $3 \mathrm{D}$ perovskite underneath, which leads to local passivation and enhanced performance in perovskite solar cells. ${ }^{42}$ Another phase with a much smaller interplanar spacing of $4.428 \AA$ in the bulk of the film comes from the $3 \mathrm{D}$ perovskite. The SEM, GIXRD and TEM results confirm that a thin layer of pure $2 \mathrm{D}$ perovskite $n-\mathrm{OA}_{2} \mathrm{~Pb}\left(I_{x} \mathrm{Br}_{1-x}\right)_{4}$ is formed after passivating the $3 \mathrm{D}$ perovskite with $n$-OABr. As illustrated in Fig. 1b, the crystal structure of the pure 2D perovskite is comprised of bulky organic cation $n$-OA sandwiched 

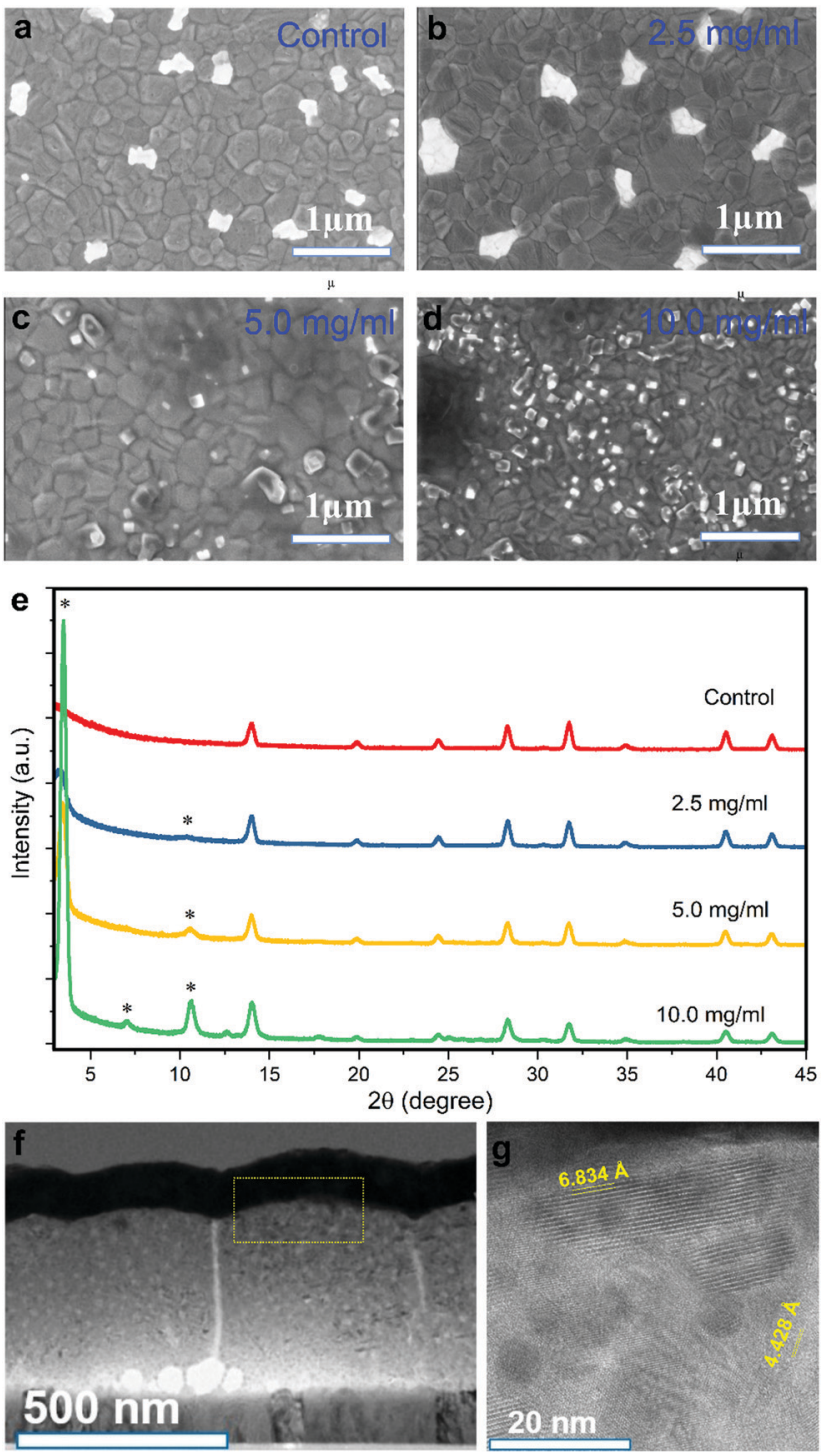

Fig. 3 Top-view scanning electron microscopy (SEM) images of perovskite films (a) control 3D perovskite film, film passivated with (b) $2.5 \mathrm{mg} \mathrm{m}^{-1}$, (c) $5.0 \mathrm{mg} \mathrm{ml}^{-1}$ and (d) $10.0 \mathrm{mg} \mathrm{ml}^{-1}$ of passivation solution. (e) Grazing incidence $X$-ray diffraction (GIXRD) of perovskite films with and without passivation layers. The * symbol represents the 2D perovskite phase. (f) Cross-sectional low-magnification bright-field transmission electron microscopy (BF-TEM) image of a passivated device with a concentration of $2.5 \mathrm{mg} \mathrm{ml}^{-1}$. (g) High-resolution TEM (HRTEM) images showing the characteristic interplanar spacing of $2 \mathrm{D}$ and 3D perovskites.

between two inorganic sheets and they are held together by Coulombic forces. ${ }^{43}$ This $2 \mathrm{D}$ structure may allow faster diffusion of $\mathrm{NO}_{2}$ molecules into the perovskite to better interact with primary amine groups in the $n$-OA cation compared with the $3 \mathrm{D}$-only perovskite device. Therefore, we hypothesize that the formation of this $2 \mathrm{D}$ perovskite layer may contribute to the enhancement in the sensor response toward $\mathrm{NO}_{2}$ gas. We note that while the response time of the $2 \mathrm{D} / 3 \mathrm{D}$ device is significantly shorter than the response time of the $3 \mathrm{D}$ device, the recovery time of the $2 \mathrm{D} / 3 \mathrm{D}$ device is only slightly lower than the recovery time of the 3D device. We speculate that the desorption kinetics of $\mathrm{NO}_{2}$ molecules in the $3 \mathrm{D}$ and $2 \mathrm{D} / 3 \mathrm{D}$ perovskites are similar. Since the recovery of the device mainly comes from the desorption process when $\mathrm{NO}_{2}$ gas is pumped out, ${ }^{44}$ a very close recovery time on the $2 \mathrm{D} / 3 \mathrm{D}$ and $3 \mathrm{D}$ devices is obtained. Because this phenomenon is quite complicated, it requires further research work especially in the molecular simulation to deeply investigate it. When the concentration of the passivation layer is $10.0 \mathrm{mg} \mathrm{ml}^{-1}$, the $2 \mathrm{D}$ layer thickness increases to approximately $50 \mathrm{~nm}$ as determined by the cross-sectional SEM results in Fig $\mathrm{S} 4$ (ESI $\dagger$ ), and the 2D layer fully covers the 3D layer underneath. We tested the performance of $2 \mathrm{D} / 3 \mathrm{D}$ perovskite sensor devices with high concentration of the passivation solution (5.0 mg ml $\mathrm{m}^{-1}$ and $10.0 \mathrm{mg} \mathrm{ml}^{-1}$ ). As shown in Fig. S5 (ESI $\dagger$ ), the response becomes smaller than the control device without any passivation solution. This is due to the nonconductive property of the 2D layer coming from its horizontal crystal plane arrangement, which hinders the current flow in the device when the 2D layer becomes excessively thick and fully covers the 3D layer underneath. ${ }^{45,46}$ Thus, the 2D/3D perovskite sensor reaches the optimal performance with a low concentration of $2.5 \mathrm{mg} \mathrm{ml}^{-1}$ for the passivation precursor.

To further investigate the enhancement performance in the 2D/3D perovskite sensor device, steady state photoluminescence (PL) and time-resolved PL measurements were used to examine the electronic properties of the mixed-dimensional perovskite films. As shown in Fig. $4 \mathrm{a}$ and b, the PL intensity is strongly enhanced in the $2 \mathrm{D} / 3 \mathrm{D}$ perovskite as compared to the $3 \mathrm{D}$ perovskite. In addition, the charge carrier lifetime is also greatly improved in the $2 \mathrm{D} / 3 \mathrm{D}$ perovskite. We also examined the PL images of the $3 \mathrm{D}$ and $2 \mathrm{D} / 3 \mathrm{D}$ perovskite films as presented in Fig. 4c and d, respectively. The 2D/3D perovskite shows much stronger and more uniform PL intensity than the $3 \mathrm{D}$ perovskite. This indicates that the $2 \mathrm{D}$ layer has passivated the defects on the $3 \mathrm{D}$ perovskite surface, hence reducing the recombination loss due to those defects. As the recombination centres might reduce the current flowing through the device in the presence of $\mathrm{NO}_{2}$ gas. It is highly possible that the reduction in recombination loss in the $2 \mathrm{D} / 3 \mathrm{D}$ perovskite would contribute to the enhanced gas sensing current in the $2 \mathrm{D} / 3 \mathrm{D}$ perovskite sensor as compared to that of the $3 \mathrm{D}$ counterpart (Fig. 2a and b).

\section{Improvement in the moisture stability of mixed-dimensional perovskite-based gas sensors}

One of the major issues related to the practical use of perovskite-based sensors is their ambient stability. We first tested the short-term operation of both the $3 \mathrm{D}$ and $2 \mathrm{D} / 3 \mathrm{D}$ perovskite sensors toward $8 \mathrm{ppm}$ of $\mathrm{NO}_{2}$ gas in a $40 \%$ relative humidity $(\mathrm{RH})$ environment. As shown in Fig. S6 (ESI $\dagger$ ), both devices operate reliably in the $40 \% \mathrm{RH}$ environment for over 30 minutes. However, the response of the $2 \mathrm{D} / 3 \mathrm{D}$ device to $8 \mathrm{ppm} \mathrm{NO}_{2}$ in the $40 \% \mathrm{RH}$ environment is similar to the response in the dry environment, while the response of the $3 \mathrm{D}$ device to $8 \mathrm{ppm} \mathrm{NO}_{2}$ in the $40 \% \mathrm{RH}$ environment is significantly lower than the response in the dry environment. This indicates that the $2 \mathrm{D} / 3 \mathrm{D}$ perovskite $\mathrm{NO}_{2}$ sensor is less 

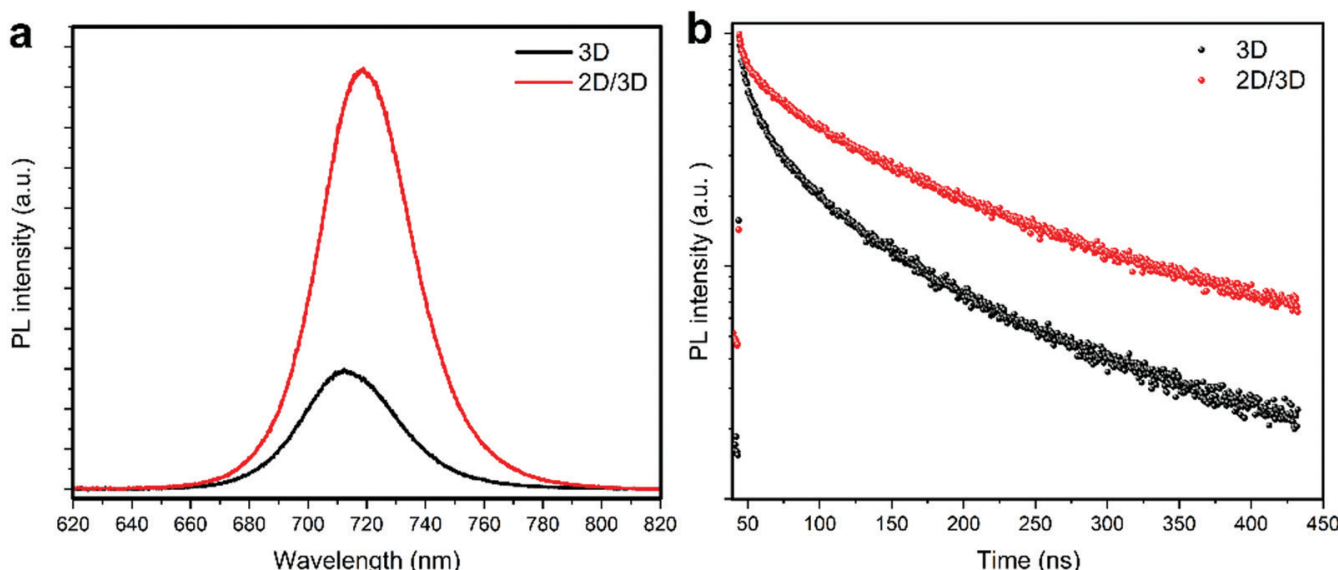

C
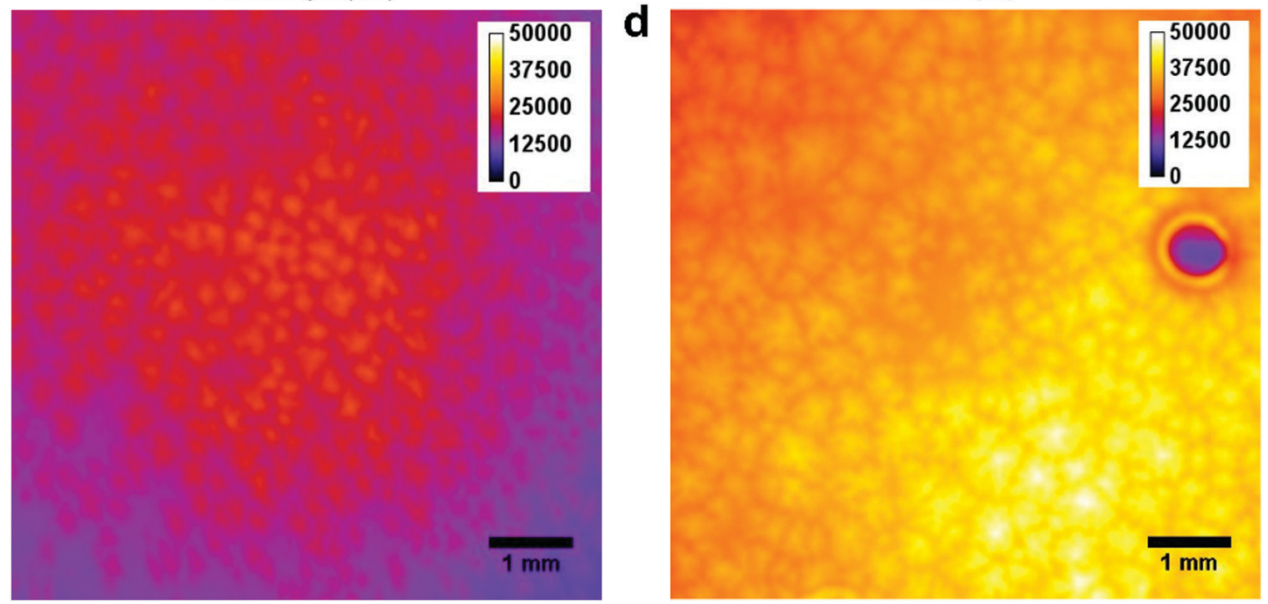

Fig. 4 (a) Steady state photoluminescence (PL) of perovskite films. (b) Time-resolved PL of perovskite films. PL images of a (c) control perovskite film and (d) passivated perovskite film.

affected by the presence of moisture compared to the $3 \mathrm{D}$ perovskite device. The long-term stability of the fabricated sensor devices by storing them under ambient conditions with relative humidity $(\mathrm{RH})$ ranging from $30-80 \%$ was examined. As shown in Fig. 5a, the absorbance of the 3D perovskite film is quickly decreased after 6, 14 and 22 days of storage. In addition, the absorbance spectrum develops a sharp absorbance peak at $\sim 450 \mathrm{~nm}$, which indicates the formation of the $\mathrm{PbI}_{2}$ phase. This irreversible degradation is due to hydrolysis reactions between water molecules with the organic species in the perovskite composition, releasing the volatile organic compounds (methylammonium $\mathrm{CH}_{3} \mathrm{NH}_{3}$, formamidinium $\mathrm{CH}\left(\mathrm{NH}_{2}\right)_{2}$, $\mathrm{HI}$, and $\mathrm{HBr}$ ) and finally converting the perovskite black phase to the $\mathrm{PbI}_{2}$ yellow phase. ${ }^{47,48}$ It is essential to tackle this degradation issue in perovskite-based sensors since the OIMHP perovskite is the active material for the detection of $\mathrm{NO}_{2}$ and the devices cannot be encapsulated. In comparison, the absorbance spectra of the 2D/3D perovskite film only show minor changes over the same period. Fig. $5 \mathrm{c}$ shows the normalized absorbance of the perovskite films at a wavelength of $660 \mathrm{~nm}$ over time, which clearly exemplifies the superior ambient stability of the $2 \mathrm{D} / 3 \mathrm{D}$ perovskite film over the 3D-only perovskite film. The inset of Fig. $5 \mathrm{a}$ and $\mathrm{b}$ displays the contact angle of the $3 \mathrm{D}$ and $2 \mathrm{D} / 3 \mathrm{D}$ perovskite films to water. The contact angle of the $3 \mathrm{D}$ perovskite film is $45.8^{\circ}$, while the contact angle of the $2 \mathrm{D} / 3 \mathrm{D}$ perovskite film greatly increases to $90.6^{\circ}$. This indicates that the perovskite film becomes hydrophobic after the deposition of a top 2D layer, and this explains the great improvement in the ambient stability of the $2 \mathrm{D} / 3 \mathrm{D}$ perovskite film. The hydrophobicity of the 2D layer comes from the large organic cations with a hydrocarbon chain surface which separate the water from the underlying 3D perovskite layer. ${ }^{49}$ The long-term stability of the $3 \mathrm{D}$ and $2 \mathrm{D} / 3 \mathrm{D}$ perovskite sensors was tested, and the normalized sensor response of the devices is shown in Fig. $5 d$. It can be observed that in the first 4 days, both devices degrade greatly although the $2 \mathrm{D} / 3 \mathrm{D}$ sensor is slightly more stable than the $3 \mathrm{D}$ counterpart. The initial degradation in the sensor response of both devices could be ascribed to the early-stage decomposition of perovskite into $\mathrm{PbI}_{2}$ as demonstrated in Fig. 5a and b. The release of organic compounds (methylammonium and formamidinium) with amine groups reduces the interaction between $\mathrm{NO}_{2}$ gas and the active perovskite layer. After 5 days, the response of the $2 \mathrm{D} / 3 \mathrm{D}$ device become stable until day 22 while the response of the $3 \mathrm{D}$ sensor device kept decreasing and the device stopped working after 13 days under ambient conditions. The 2D/3D sensor device was continuously tested, and the device 
a
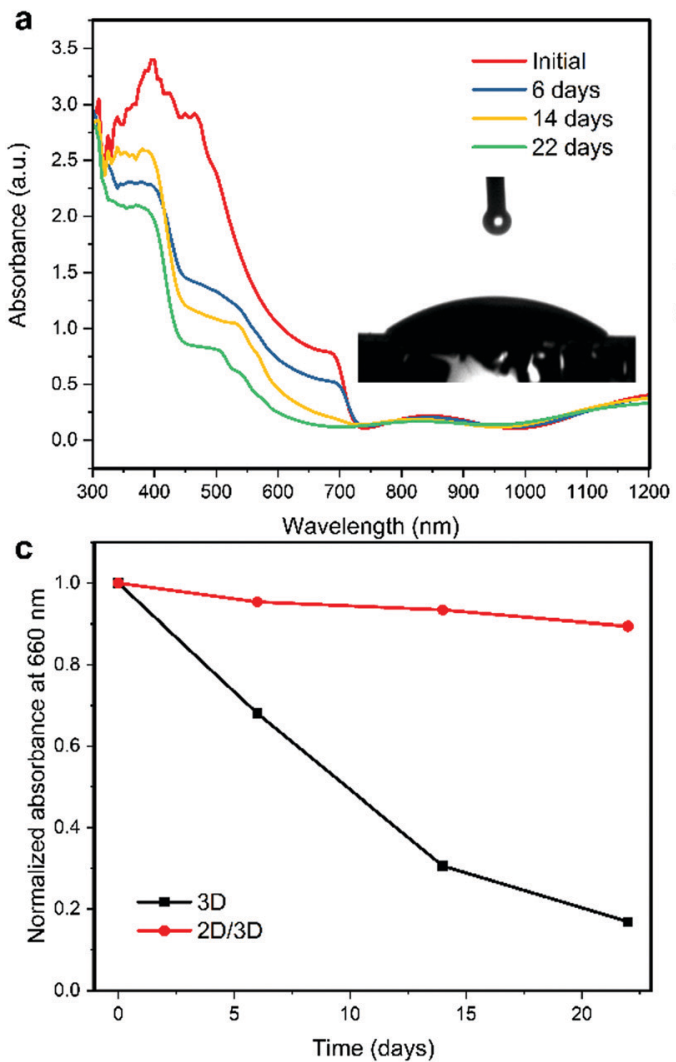
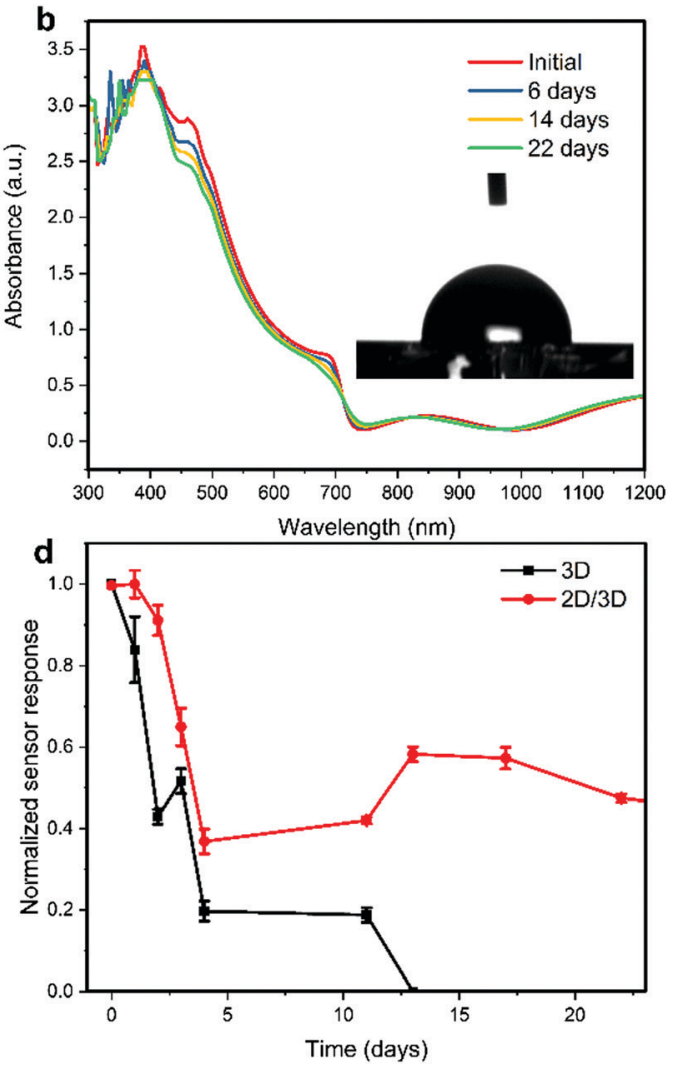

Fig. 5 The absorbance spectra of the (a) 3D perovskite film and (b) 2D/3D perovskite film under ambient conditions with the relative humidity ranging from $30 \%$ to $80 \%$ for up to 22 days under ambient conditions. (c) Normalized absorbance of the perovskite films at $660 \mathrm{~nm}$ over 22 days. (d) Normalized sensor response of 3D and 2D/3D perovskite $\mathrm{NO}_{2}$ gas sensors under ambient conditions for 22 days.

still shows good response after 57 days, retaining almost $25 \%$ of the initial response (Fig. S7, ESI $\dagger$ ). The results demonstrate that the mixed-dimensional 2D/3D perovskites greatly improve the ambient stability of perovskite-based gas sensors.

\section{Conclusions}

In summary, we have presented a strategy to improve both the performance and stability of perovskite $\mathrm{NO}_{2}$ gas sensors. By passivating 3D perovskite films with a long alkyl chain organic cation n-octylammonium bromide to form mixeddimensional 2D/3D perovskite films, the performance and ambient stability of perovskite-based $\mathrm{NO}_{2}$ gas sensors are greatly enhanced. This can be ascribed to the formation of the ultrathin 2D layer on the surface of the 3D perovskite, which increase the interaction between the $\mathrm{NO}_{2}$ gas and the amine groups in both the $3 \mathrm{D}$ and $2 \mathrm{D}$ perovskites. In addition, the $2 \mathrm{D}$ layer passivates the defects on the $3 \mathrm{D}$ perovskite surface acting as recombination centres. The 2D/3D perovskite sensor shows good selectivity toward $\mathrm{NO}_{2}$, excellent sensitivity of $6.3 \pm 0.83$ times per ppm and quick response/recovery times of $5.7 \mathrm{~s}$ and $12.7 \mathrm{~s}$, respectively. Most importantly, the device demonstrates superior stability under ambient conditions for almost two months, shedding light on the design of stable perovskite based gas sensors for practical applications.

\section{Author contributions}

The Duong: conceptualization, methodology, investigation, writing - original draft; Alishba T. John: methodology, validation, formal analysis, writing - review \& editing; Hongjun Chen: conceptualization, methodology, writing - review \& editing; Huyen Pham: investigation, writing - review \& editing; Krishnan Murugappan: investigation, writing - review \& editing; Thanh Tran-Phu: investigation, writing - review \& editing; Antonio Tricoli: resources, supervision, funding acquisition, writing review \& editing; Kylie Catchpole: resources, supervision, funding acquisition, writing - review \& editing.

\section{Conflicts of interest}

There are no conflicts to declare.

\section{Acknowledgements}

Part of the experiment was performed at Australian National Fabrication Facility (ANFF) ACT Node and Centre for Advanced Microscopy (CAM) ACT Node. T. D acknowledges the financial support of Postdoc Fellowships from the Australian Centre for Advanced Photovoltaics (ACAP). A. T. J, K. M and A. T acknowledge the financial support of Our Health in Our Hands (OHIOH), 
a strategic initiative of the Australian National University, which aims to transform healthcare by developing new personalised health technologies and solutions in collaboration with patients, clinicians, and health care providers.

\section{References}

1 R. Ehrlich, Effect of nitrogen dioxide on resistance to respiratory infection, Bacteriol. Rev., 1966, 30(3), 604-614.

2 M. A. Bauer, M. J. Utell, P. E. Morrow, D. M. Speers and F. R. Gibb, Inhalation of 0.30 ppm Nitrogen Dioxide Potentiates Exercise-induced Bronchospasm in Asthmatics, Am. Rev. Respir. Dis., 1986, 134(5), 1203-1208.

3 H. E. Stokinger, Evaluation of the Hazards of Ozone and Oxides of Nitrogen-Factors Modifying Acute Toxicity, J. Air Pollut. Control Assoc., 1958, 8(2), 129-137.

4 T. Y. Wong, Smog induces oxidative stress and microbiota disruption, J. Food Drug Anal., 2017, 25(2), 235-244.

5 S. Paul and M. Joseph, Polypyrrole functionalized with FePcTSA for NO2 sensor application, Sens. Actuators, B, 2009, 140(2), 439-444.

6 S. T. Navale, M. A. Chougule, V. B. Patil and A. T. Mane, Highly sensitive, reproducible, selective and stable CSApolypyrrole NO2 sensor, Synth. Met., 2014, 189, 111-118.

7 H. Bai and G. Shi, Gas Sensors Based on Conducting, Polymers, 2007, 7(3), 267-307.

8 M. J. Lefferts, B. I. Armitage, K. Murugappan and M. R. Castell, PEDOT percolation networks for reversible chemiresistive sensing of NO2, RSC Adv., 2021, 11(37), 22789-22797.

9 W.-J. Liou and H.-M. Lin, Nanohybrid TiO2/carbon black sensor for NO2 gas, China Particuol., 2007, 5(3), 225-229.

10 S.-W. Choi, J. Kim and Y. T. Byun, Highly sensitive and selective $\mathrm{NO} 2$ detection by $\mathrm{Pt}$ nanoparticles-decorated single-walled carbon nanotubes and the underlying sensing mechanism, Sens. Actuators, B, 2017, 238, 1032-1042.

11 T. Helbling, C. Hierold, L. Durrer, C. Roman, R. Pohle and M. Fleischer, Suspended and non-suspended carbon nanotube transistors for NO2 sensing - A qualitative comparison, Phys. Status Solidi B, 2008, 245(10), 2326-2330.

12 H. Y. Jeong, D.-S. Lee, H. K. Choi, D. H. Lee, J.-E. Kim, J. Y. Lee, W. J. Lee, S. O. Kim and S.-Y. Choi, Flexible roomtemperature NO2 gas sensors based on carbon nanotubes/ reduced graphene hybrid films, Appl. Phys. Lett., 2010, 96(21), 213105.

13 R. Pearce, T. Iakimov, M. Andersson, L. Hultman, A. L. Spetz and R. Yakimova, Epitaxially grown graphene based gas sensors for ultra sensitive NO2 detection, Sens. Actuators, B, 2011, 155(2), 451-455.

14 A. Sanger, S. B. Kang, M. H. Jeong, C. U. Kim, J. M. Baik and K. J. Choi, All-Transparent NO2 Gas Sensors Based on Freestanding Al-Doped ZnO Nanofibers, ACS Appl. Electron. Mater., 2019, 1(7), 1261-1268.

15 Y.-S. Shim, L. Zhang, D. H. Kim, Y. H. Kim, Y. R. Choi, S. H. Nahm, C.-Y. Kang, W. Lee and H. W. Jang, Highly sensitive and selective $\mathrm{H} 2$ and $\mathrm{NO} 2$ gas sensors based on surface-decorated WO3 nanoigloos, Sens. Actuators, B, 2014, 198, 294-301.

16 R. Kumar, O. Al-Dossary, G. Kumar and A. Umar, Zinc Oxide Nanostructures for NO2 Gas-Sensor Applications: A Review, Nano-Micro Lett., 2015, 7(2), 97-120.

17 M. Chen, Z. Wang, D. Han, F. Gu and G. Guo, Highsensitivity NO2 gas sensors based on flower-like and tubelike ZnO nanomaterials, Sens. Actuators, B, 2011, 157(2), 565-574.

18 C.-J. Chang, C.-Y. Lin, J.-K. Chen and M.-H. Hsu, Ce-doped ZnO nanorods based low operation temperature $\mathrm{NO} 2$ gas sensors, Ceram. Int., 2014, 40(7, Part B), 10867-10875.

19 S. Kumar, V. Pavelyev, P. Mishra, N. Tripathi, P. Sharma and F. Calle, A review on $2 \mathrm{D}$ transition metal di-chalcogenides and metal oxide nanostructures based NO2 gas sensors, Mater. Sci. Semicond. Process., 2020, 107, 104865.

20 S. De Wolf, J. Holovsky, S.-J. Moon, P. Löper, B. Niesen, M. Ledinsky, F.-J. Haug, J.-H. Yum and C. Ballif, Organometallic Halide Perovskites: Sharp Optical Absorption Edge and Its Relation to Photovoltaic Performance, J. Phys. Chem. Lett., 2014, 5(6), 1035-1039.

21 M. A. Green, A. Ho-Baillie and H. J. Snaith, The emergence of perovskite solar cells, Nat. Photonics, 2014, 8(7), 506-514.

22 S. D. Stranks and H. J. Snaith, Metal-halide perovskites for photovoltaic and light-emitting devices, Nat. Nanotechnol., 2015, 10(5), 391-402.

23 H.-S. Kim, J.-Y. Seo and N.-G. Park, Material and Device Stability in Perovskite Solar Cells, ChemSusChem, 2016, 9(18), 2528-2540.

24 Q. Dong, L. Lei, J. Mendes and F. So, Operational stability of perovskite light emitting diodes, J. Phys. Mater., 2020, 3(1), 012002.

25 Z. Zhu, Q. Sun, Z. Zhang, J. Dai, G. Xing, S. Li, X. Huang and W. Huang, Metal halide perovskites: stability and sensingability, J. Mater. Chem. C, 2018, 6(38), 10121-10137.

26 H. Chen, M. Zhang, R. Bo, C. Barugkin, J. Zheng, Q. Ma, S. Huang, A. W. Y. Ho-Baillie, K. R. Catchpole and A. Tricoli, Superior Self-Powered Room-Temperature Chemical Sensing with Light-Activated Inorganic Halides Perovskites, Small, 2018, 14(7), 1702571.

27 G. Kakavelakis, E. Gagaoudakis, K. Petridis, V. Petromichelaki, V. Binas, G. Kiriakidis and E. Kymakis, Solution Processed $\mathrm{CH}_{3} \mathrm{NH}_{3} \mathrm{PbI}_{3-x} \mathrm{Cl}_{x}$ Perovskite Based Self-Powered Ozone Sensing Element Operated at Room Temperature, ACS Sens., 2018, 3(1), 135-142.

28 A. Maity, S. Mitra, C. Das, S. Siraj, A. K. Raychaudhuri and B. Ghosh, Universal sensing of ammonia gas by family of lead halide perovskites based on paper sensors: Experiment and molecular dynamics, Mater. Res. Bull., 2021, 136, 111142.

29 Y. Zhuang, W. Yuan, L. Qian, S. Chen and G. Shi, Highperformance gas sensors based on a thiocyanate ion-doped organometal halide perovskite, Phys. Chem. Chem. Phys., 2017, 19(20), 12876-12881.

30 X. Fu, S. Jiao, N. Dong, G. Lian, T. Zhao, S. Lv, Q. Wang and D. Cui, $\mathrm{A} \mathrm{CH}_{3} \mathrm{NH}_{3} \mathrm{PbI}_{3}$ film for a room-temperature $\mathrm{NO} 2$ gas 
sensor with quick response and high selectivity, $R S C A d v$. 2018, 8(1), 390-395.

31 H. Chen, M. Zhang, B. Xing, X. Fu, R. Bo, H. K. Mulmudi, S. Huang, A. W. Y. Ho-Baillie, K. R. Catchpole and A. Tricoli, Superior Self-Charged and -Powered Chemical Sensing with High Performance for NO2 Detection at Room Temperature, Adv. Opt. Mater., 2020, 8(11), 1901863.

32 T. Duong, H. Pham, Y. Yin, J. Peng, M. A. Mahmud, Y. Wu, H. Shen, J. Zheng, T. Tran-Phu, T. Lu, L. Li, A. Kumar, G. G. Andersson, A. Ho-Baillie, Y. Liu, T. White, K. Weber and K. Catchpole, Efficient and stable wide bandgap perovskite solar cells through surface passivation with long alkyl chain organic cations, J. Mater. Chem. A, 2021, 9(34), 18454-18465.

33 P. Gao, A. R. Bin Mohd Yusoff and M. K. Nazeeruddin, Dimensionality engineering of hybrid halide perovskite light absorbers, Nat. Commun., 2018, 9(1), 5028.

34 D. Walter, Y. Wu, T. Duong, J. Peng, L. Jiang, K. C. Fong and K. Weber, On the Use of Luminescence Intensity Images for Quantified Characterization of Perovskite Solar Cells: Spatial Distribution of Series Resistance, Adv. Energy Mater., 2018, 8(2), 1701522.

35 T. Duong, Y. Wu, H. Shen, J. Peng, S. Zhao, N. Wu, M. Lockrey, T. White, K. Weber and K. Catchpole, Light and elevated temperature induced degradation (LeTID) in perovskite solar cells and development of stable semitransparent cells, Sol. Energy Mater. Sol. Cells, 2018, 188, 27-36.

36 M. W. G. Hoffmann, L. Mayrhofer, O. Casals, L. Caccamo, F. Hernandez-Ramirez, G. Lilienkamp, W. Daum, M. Moseler, A. Waag, H. Shen and J. D. Prades, A Highly Selective and SelfPowered Gas Sensor Via Organic Surface Functionalization of p-Si/n-ZnO Diodes, Adv. Mater., 2014, 26(47), 8017-8022.

37 O. Casals, N. Markiewicz, C. Fabrega, I. Gràcia, C. Cané, H. S. Wasisto, A. Waag and J. D. Prades, A Parts Per Billion (ppb) Sensor for NO2 with Microwatt $(\mu \mathrm{W})$ Power Requirements Based on Micro Light Plates, ACS Sens., 2019, 4(4), 822-826.

38 J. D. Prades, R. Jimenez-Diaz, M. Manzanares, F. HernandezRamirez, A. Cirera, A. Romano-Rodriguez, S. Mathur and J. R. Morante, A model for the response towards oxidizing gases of photoactivated sensors based on individual $\mathrm{SnO} 2$ nanowires, Phys. Chem. Chem. Phys., 2009, 11(46), 10881-10889.

39 T. Duong, H. K. Mulmudi, H. Shen, Y. Wu, C. Barugkin, Y. O. Mayon, H. T. Nguyen, D. Macdonald, J. Peng, M. Lockrey, W. Li, Y.-B. Cheng, T. P. White, K. Weber and K. Catchpole, Structural engineering using rubidium iodide as a dopant under excess lead iodide conditions for high efficiency and stable perovskites, Nano Energy, 2016, 30, 330-340.
40 D. J. Kubicki, D. Prochowicz, A. Hofstetter, S. M. Zakeeruddin, M. Grätzel and L. Emsley, Phase Segregation in Cs-, Rb- and K-Doped Mixed-Cation (MA)x(FA)1-xPbI3 Hybrid Perovskites from Solid-State NMR, J. Am. Chem. Soc., 2017, 139(40), 14173-14180.

41 T. Duong, H. Pham, Y. Yin, J. Peng, M. A. Mahmud, Y. Wu, H. Shen, J. Zheng, T. Tran-Phu, T. Lu, L. Li, A. Kumar, G. G. Andersson, A. Ho-Baillie, Y. Liu, T. White, K. Weber and K. Catchpole, Efficient and stable wide bandgap perovskite solar cells through surface passivation with long alkyl chain organic cations, J. Mater. Chem. A, 2021, 9, 18454.

42 M. A. Mahmud, T. Duong, Y. Yin, H. T. Pham, D. Walter, J. Peng, Y. Wu, L. Li, H. Shen, N. Wu, N. Mozaffari, G. Andersson, K. R. Catchpole, K. J. Weber and T. P. White, Double-Sided Surface Passivation of 3D Perovskite Film for High-Efficiency Mixed-Dimensional Perovskite Solar Cells, Adv. Funct. Mater., 2020, 30(7), 1907962.

43 G. Grancini and M. K. Nazeeruddin, Dimensional tailoring of hybrid perovskites for photovoltaics, Nat. Rev. Mater., 2019, 4(1), 4-22.

44 R. R. Kumar, T. Murugesan, A. Dash, C.-H. Hsu, S. Gupta, A. Manikandan, A. K. Anbalagan, C.-H. Lee, N.-H. Tai, Y.-L. Chueh and H.-N. Lin, Ultrasensitive and light-activated NO2 gas sensor based on networked MoS2/ZnO nanohybrid with adsorption/desorption kinetics study, Appl. Surf. Sci., 2021, 536, 147933.

45 D. H. Cao, C. C. Stoumpos, O. K. Farha, J. T. Hupp and M. G. Kanatzidis, 2D Homologous Perovskites as LightAbsorbing Materials for Solar Cell Applications, J. Am. Chem. Soc., 2015, 137(24), 7843-7850.

46 S. Ma, M. Cai, T. Cheng, X. Ding, X. Shi, A. Alsaedi, T. Hayat and Y. Ding, Tan, Z. a.; Dai, S., Two-dimensional organicinorganic hybrid perovskite: from material properties to device applications, Sci. China Mater., 2018, 61(10), 1257-1277.

47 J. M. Frost, K. T. Butler, F. Brivio, C. H. Hendon, M. van Schilfgaarde and A. Walsh, Atomistic Origins of HighPerformance in Hybrid Halide Perovskite Solar Cells, Nano Lett., 2014, 14(5), 2584-2590.

48 Z. Song, A. Abate, S. C. Watthage, G. K. Liyanage, A. B. Phillips, U. Steiner, M. Graetzel and M. J. Heben, Perovskite Solar Cell Stability in Humid Air: Partially Reversible Phase Transitions in the $\mathrm{PbI}_{2}-\mathrm{CH}_{3} \mathrm{NH}_{3} \mathrm{I}-\mathrm{H}_{2} \mathrm{O}$ System, Adv. Energy Mater, 2016, 6(19), 1600846.

49 H. Zheng, G. Liu, L. Zhu, J. Ye, X. Zhang, A. Alsaedi, T. Hayat, X. Pan and S. Dai, The Effect of Hydrophobicity of Ammonium Salts on Stability of Quasi-2D Perovskite Materials in Moist Condition, Adv. Energy Mater., 2018, 8(21), 1800051. 